\title{
El Dr. Jérôme Lejeune, descubridor del síndrome de Down
}

\author{
Dr. Jérôme Lejeune, \\ Discoverer of Down's Syndrome
}

\author{
IGNACIO OLÁBARRI GORTÁZAR \\ Universidad de Navarra \\ iolabarr@unav.es
}

Aude Dugast, Jérôme Lejeune. La libertad del sabio, Madrid, Encuentro, 202I.

Existe abundante bibliografía de calidad sobre la vida y obra del médico y genetista francés Jérome Lejeune. Aude Dugast ha hecho varias aportaciones, incluyendo el libro del que parte este informe'. Recojo en nota otras contribuciones de calidad ${ }^{2}$. En su origen, este informe tiene unas motivaciones personales que habitualmente no se dan cuando se trata de otros libros.

I Dugast, Aude, Jérôme Lejeune: portrait spirituel au fil des vertus, París, Salvator, 2021; Dugast, Aude y Michael J. Millen, Jérôme Lejeune: a man of science and conscience, San Francisco, Ignatius Press, 202I. Desgraciadamente, ninguno de estos dos libros ha estado a mi disposición.

2 Lejeune, Clara, Dr. Lejeune: el amor a la vida, Madrid, Palabra, 1999; Lejeune-Gaymard, Clara (es la misma autora), La dicha de vivir. Jérôme Lejeune, mi padre, Madrid, Rialp, 2012 (ed. orig. francesa, Paris, Fleurus Éditions, 1997). Clara Lejeune publicó ediciones en inglés de su libro en San Francisco, Ignatius Press, 2000 y 2010, y en Paris, Jérôme Lejeune Foundation, 2010; Le Méné, Jean-Marie, El profesor Lejeune. Fundador de la genética moderna, Madrid, Marova, 2013 (ed. original francesa, París, Groupe Fleurus-Mame, 1997). El autor es yerno de Lejeune y presidente de la Fundación Jérôme Lejeune; Bernet, Anne, Jérôme Lejeune, biographie, Paris, Presses de la Renaissance, 2004; González, Enrique, Dejar vivir. Marías y Lejeune en defensa de la vida, Madrid, Rialp, 2013; Evrard. Gaëtan y Dominique Bar, Jérôme Lejeune, Serviteur de la vie, Paris, Éditions du Triomphe, 2018; Esparza, Javier, Defender, luchar, amar, curar: la fascinante vida del descubridor del origen del Síndrome de Down, Madrid, Libros Libres, 2019. Como es natural, el propio Dr. Lejeune publicó muchos artículos de carácter científico que no tiene sentido recoger aquí.

MEMORIA Y CIVILIZACIÓN 24 (202I): 639-653 [I-I5] [ISSN: II39-0I07; ISSN-e: 2254-6367]

DOI: https://doi.org//0.1558I/00I.24.023 
Para mí, antiguo alumno, profesor y actualmente profesor emérito de la Universidad de Navarra, ya es un estímulo el hecho de que el profesor Lejeune fuera nombrado doctor honoris causa por nuestra Universidad en 1974. Pero hay un segundo motivo, también de carácter personal, más antiguo y más cercano.

El 8 de abril de 1965 nació mi hermano Juan, el último de los diez Olábarri Gortázar, con el llamado (hay terminologías más precisas, como veremos) Síndrome de Down. Aconsejada por amigas de Bilbao y de Madrid, que habían pasado por la misma experiencia, mamá, que siempre que en la familia había habido problemas de salud serios había confiado en la Clínica Universitaria de Navarra, viajó a París a la consulta del Dr. Lejeune para que le aconsejara sobre cómo educar a su hijo. "Sito», el señorito, como le llamábamos con cariño sus hermanos, nunca ha aprendido a leer y escribir y entre los compañeros y monitores de los talleres de la Asociación Uribe-Costa, que ayudó a fundar mi madre con el apoyo financiero de la Diputación de Vizcaya, tenía fama de vago, aunque fuera siempre muy popular.

Pero ha llegado ya el momento de hablar del libro de Aude Dugast sobre el doctor Lejeune. Como tantos otros, comienza por el final, por las manifestaciones de la amistad, y de amistad no de una persona cualquiera, sino del Santo Padre Juan Pablo II, quien en 1997 se acordaba perfectamente de la tristeza que sintió cuando recibió la noticia de la muerte de su amigo Jérôme el 3 de abril de 1994, en la mañana de la Pascua. Tres años después, aprovechando la celebración en París de las Jornadas Mundiales de la Juventud, el Papa se acercó al pueblecito de Chalo-Saint-Mars para orar ante la tumba de su amigo.

El 4 de abril de 1994, Juan Pablo II le envió al cardenal Lustiger, arzobispo de París, una carta de homenaje en la que expresaba su reconocimiento por el carisma del profesor Lejeune:

Esta muerte testimonia con mayor fuerza la vida a la que el hombre está llamado en Jesucristo. Durante toda la vida de nuestro hermano Jérôme, esta llamada representó una línea directriz. Como sabio biólogo, sintió pasión por la vida. En su campo fue una de las mayores autoridades mundiales. [...]

Llegó a ser uno de los más ardientes defensores de la vida, especialmente de la vida de los niños por nacer que, en nuestra civilización contemporánea, frecuentemente están amenazados, hasta el punto de que se puede pensar en una amenaza programada. Hoy esta amenaza se extiende igualmente a los ancianos y a los enfermos. [...] El profesor Lejeune asumió plenamente la responsabilidad particular del sabio, dispuesto a convertirse en un signo de contradicción, sin tener en cuenta las presiones externas ejercidas por la sociedad permisiva ni el ostracismo al que lo habían condenado.

Nos hallamos hoy ante la muerte de un gran cristiano del siglo XX, un hombre para el que la defensa de la vida llegó a ser un apostolado. [...] En particular, 


\section{EL DR. JÉRÔME LEJEUNE}

quisiera agradecerle el haber tomado la iniciativa de la creación de la Pontificia Academia para la Vida» (pp. 12-13).

Es el momento de pasar del final al inicio. El 19 de junio de 1926, segundo hijo de Pierre y de Massa, nacía en Montrouge, muy cerca de París, Jérôme Lejeune. Una semana después, fue bautizado en la iglesia de Saint-Jacques-le Majeur de Montrouge, con su abuelo materno y su abuela paterna como padrinos.

Durante la semana los hermanos van a la escuela Sainte Jeanne d'Arc, una pequeña institución para chicas, dirigida por monjas, que acepta niños hasta los seis años. Por su parte, sus padres, profundamente religiosos, les enseñan el amor a Dios y a la Iglesia y todos los días, hasta la entrada en el colegio, hacen la oración de la noche con ellos de rodillas ante el crucifijo. "Massa les enseña a decir con fe: "Yo soy católico romano", y esta identidad les parece tan natural como la de ser franceses» (p. 2I).

Las vacaciones de verano tienen lugar en Normandía, Bretaña o en la casa de los abuelos Lermat en Royan. A la vuelta de las vacaciones de 1932, y teniendo en cuenta que Montrouge se urbaniza cada vez más, Pierre decide comprar una casa con jardín en Étampes, una gloria tanto para su mujer como para sus hijos. Ese mismo año llega entre dificultades el tercer hermano, Rémy.

Un año después, cuando Jérôme cumple los siete años, los dos mayores se integran en el colegio Stanislas de París. Allí reina una severa disciplina, el nivel de los estudios es elevado y las prácticas de piedad de rigor. Jérôme "se introduce en el molde sin excesivas dificultades»; no se distingue por sus notas, pero entabla pronto amistad con sus compañeros y aprecia a los padres que enseñan en el Stanislas, en particular al padre Balsan, su profesor de latín, del que admira sobre todo su amor por Dios. Su madre tiene los ojos puestos en el primogénito y no valora las felicitaciones que recibe Jérôme. Su padre da poco valor a las notas, pero sí se interesa por la calidad de la enseñanza recibida y que sus hijos alimenten su inteligencia mediante la belleza y la búsqueda de la verdad.

En 1936 llega el Frente Popular al poder y en la destilería familiar comienzan pronto los problemas, que se resuelven con una subida de sueldos y con la impresión que causa en los hijos ver a sus amigos de ayer convertidos en contestatarios. Es el comienzo de una cadena de acontecimientos negativos, que alcanza su pico con el comienzo de la Segunda Guerra Mundial. Pero antes, el 6 de mayo de 1937, Jérôme recibe su comunión solemne y su confirmación en el Stanislas.

Con el comienzo de la guerra, Pierre toma una sabia decisión: sus hijos no van a ir a ningún colegio, sino que van a estudiar en casa. El primer año va a ser un año de lectura de los clásicos y Jérôme se lanza con frenesí a la lectura, haciendo dos descubrimientos que nunca olvidará: Pascal y Balzac. Fue en este tiempo cuando comenzó a interesarse por la biología y la medicina. «Este año, a 
pesar de la guerra, quedará como uno de los más agradables de la vida de ambos» (p. 28). Y, sin embargo, ven la guerra de cerca: son testigos de la entrada de los alemanes en Étampes y cómo requisan dos de las habitaciones de su casa.

Al año siguiente, $y$ dado que la guerra se prolonga, Pierre matricula a sus hijos en el liceo de Étampes. Los chicos encuentran buenos amigos y se entusiasman con el teatro. Pero la familia Lejeune, como todas las familias francesas, viven en condiciones difíciles durante estos años de guerra. Pierre se vio obligado a declararse en quiebra y vender la destilería en 1940, y su situación material se agrava. Es verdad que dispone de un trabajo en el Tribunal de comercio de París, pero se necesita más para vivir; algo que se «resuelve» cuando el ayuntamiento de Étampes huye y se le pide a Pierre que ocupe la alcaldía, una solución que acepta a pesar de haberse mantenido siempre alejado de la política.

En 1944, cuando los hermanos Lejeune van en bicicleta a París para realizar las pruebas escritas del bachillerato, los alemanes se retiran ante el avance de los aliados sin defender Étampes; pero la alegría de Pierre Lejeune dura un instante: un joven armado llama la puerta de su despacho en el ayuntamiento para comunicarle que queda destituido de sus funciones. Su familia se entera de ambas noticias el mismo día; y Massa llega a saber, poco después, "que su marido es acusado de atentar contra la seguridad del Estado y de colaboración con el enemigo» (p. 33). Se suceden los días difíciles: Pierre puede recibir a su familia en la cárcel, pero también sabe que no faltan los fusilamientos que siguen a juicios sumarios en este periodo de la Depuración. Cuenta con amigos, pero también unos individuos poco recomendables acuden a su casa y dicen a su familia que, si no se marchan de Étampes, Pierre jamás será liberado. Es entonces cuando se descubre la fuerza de la personalidad de Massa, que se transmite a sus hijos, quienes, «de pie junto a ella, se convierten en unos hombres» (p. 35). Finalmente, la víspera de Navidad, la administración penitenciaria, siguiendo la tradición, libera a algunos presos, entre ellos a Pierre, convertido en un anciano. "Cuando sus hijos le preguntan: "Papá, cuando estabas en la cárcel, y ante tanta injusticia, illegaste a dudar? ¿Llegaste a dudar de Dios?". "No, queridos hijos, nunca he dudado de Dios. Al contrario, ha sido mi fe lo que me ha mantenido en vida. Ahora bien, dudar de los hombres, eso si". " ¿Y el odio, papá? Tienes que odiar a todos esos infames que estaban dispuestos a sacrificarte para ocultar sus propias vilezas". "No, jamás he odiado a nadie. Afortunadamente, pues el odio me habría destrozado. Y, además, me parece que todos esos infames, como vosotros les llamáis, no saben lo que hacen» (pp. 35-36). Pero, aunque el magistrado ha dictado el sobreseimiento de la causa por falta de acusación, sus enemigos políticos continúan sus presiones sobre la familia y, atemorizado, debilitado, Pierre ya no se atreve a caminar por las calles. 


\section{EL DR. JÉRÔME LEJEUNE}

Unas cuantas semanas antes de que su padre saliera de la cárcel, en octubre de 1944, Jérôme había comenzado sus estudios de medicina en París. Desplazarse cada mañana es una carrera de obstáculos. El 8 de mayo de 1945 capituló Alemania $y$, unos días más tarde, Jérôme supera con éxito los exámenes de primer curso. Continúa su interés por el teatro y ambos hermanos se hacen miembros de la Juventud Estudiante Católica. Para Jérôme comienzan las prácticas en los hospitales, que elige en función de su proximidad a Étampes: la Salpêtrière, l'Hôtel-Dieu y Laënnec. Su primera experiencia hospitalaria le entusiasma y se apasiona por la cirugía.

Otro periodo de prácticas le acerca a la pediatría, concretamente al servicio del profesor Raymond Turpin, donde descubre los misterios de la genética humana, y pronto quedará fascinado por esta disciplina. El profesor Turpin advierte el interés y la aptitud de este joven estudiante y le propone, en el transcurso de su cuarto curso de carrera, nombrarle asistente externo de su consulta. Jérôme acepta entusiasmado y Turpin le asigna de inmediato al servicio de los niños mongólicos. A partir de ese momento, sintiendo nacer un gran afecto por ellos, y a ejemplo de su maestro, que les otorga toda su atención, Jérôme aprende a conocerles y a examinarles, y empieza a descifrar hábilmente el mensaje inscrito en las líneas de sus manos.

En los años siguientes Lejeune tiene que abandonar el servicio de Turpin: intentará sin éxito aprobar el examen del externado de los hospitales de París, tiene que defender su tesis de medicina y hacer el servicio militar. En él hace dos descubrimientos importantes, dos colegas que serán sus amigos de por vida: Lucien Israël y Jean de Grouchy y con ellos da rienda suelta a sus sentimientos más profundos:

«Desde que estuve haciendo prácticas con el profesor Turpin pienso mucho en estos niños mongólicos. Estos últimos años me he apasionado por la cirugía y la genética, y como ahora me es imposible dedicarme a la cirugía (su fracaso en el examen del externado se lo impide), se me ha facilitado la elección: quisiera continuar con la genética. De hecho... cuando pienso en estos niños... sueño con encontrar las causas de su mal...». Y tras un momento de silencio, prosigue: « $¡$ Vas a ver, voy a encontrar lo que tienen y tal vez cómo curarlos!». Lucien le mira, divertido, y responde: «¡Formidable! ¡No me olvidaré de recordarte lo que me has dicho cuando ya sea una realidad!» (pp. 38-39).

La autora hace aquí un paréntesis para presentar otra de las realidades que más profundamente van a marcar a Jérôme: la danesa Birthe Bringsted, con la que se encuentra por primera vez en la biblioteca Sainte-Geneviève, en el París de 1950. La primera conversación entre Jérôme y Birthe, luterana e hija única, que había venido a París para aprender el francés, comenzó de forma casual: Birthe necesita una pluma estilográfica que Jérôme le proporciona. «El flechazo 
es inmediato". A pesar de los amorosos comienzos, que incluyen un mes de agosto en Dinamarca, invitado Jérôme por la madre de Birthe, aparece la duda y cesa la relación. Hasta que, cuando vuelven a verse en París en enero de 1952, "se dan cuenta de que ya no pueden vivir el uno sin el otro. A pesar de sus grandes diferencias y de las reticencias de los padres de Jérôme, deciden casarse, para amarse tal como son, con toda la riqueza de esta complementariedad [...] Birthe vuelve a encontrar la alegría de vivir» (pp. 42-43). Después de Dios, Birthe es el apoyo más profundo de Jérôme durante toda su vida.

"Al hacer la experiencia de este medio amor humano, Jérôme comprende que Dios es su fuente y el noviazgo se convierte en una etapa importante de su itinerario espiritual. Desde la ciencia y vida en la infancia y mantenida por costumbre a la edad de las salidas estudiantiles, descubre, al alba de su vida adulta, una alegría nueva al reconocer el amor que procede de su Padre del Cielo. Un amor potente y liberador. $Y$ Jérôme confía esta felicidad absolutamente nueva a su novia: "Esta mañana he comulgado por nosotros dos a las 8 de la mañana en la catedral. Nunca me había sentido tan feliz, tranquilo y amante de Dios"» ${ }^{3}$.

Pronto le pide Jérôme que comparta con él la fe católica. Birthe acepta de buena gana y comienza a seguir cursos de catecismo, que complementa con unas conversaciones de instrucción religiosa con su futuro suegro, cuya voz es tan contagiosa.

No es este el único asunto que llama la atención de Lejeune: en 1955 firmará su primera publicación, junto con Turpin, en torno a los efectos de las radiaciones atómicas sobre el patrimonio hereditario humano. Dichos estudios le llevarán, a los $3 \mathrm{I}$ años, a ser nombrado experto francés por el Comité científico de las Naciones Unidas sobre los efectos de las radiaciones atómicas, nombramiento que será renovado durante más de veinte años.

La boda queda fijada para cuando Jérôme acabe el servicio militar, el I de mayo, en la iglesia católica de Saint-Alban de Odense. Como sus padres, dado su estado de salud, no podían acudir, fue su hermano Philippe, junto con su joven mujer Geneviève Dormann, quienes deciden ir en moto. Ante las muestras de inquietud de Pierre, Philippe le contesta: «iDe ninguna manera voy a dejar a Jérôme casarse sin mí y sin ningún miembro de la familia!». A Pierre no le desagrada la respuesta (p. 45).

En lo laboral, prefiere aceptar la oferta del profesor Raymond Turpin, que le propone un puesto en su servicio para ocuparse de sus numerosos enfermos mongólicos, que no interesan a demasiada gente. Turpin había realizado ya inves-

\footnotetext{
${ }^{3}$ Carta a Birthe, 9 de marzo de 1952.
} 


\section{EL DR. JÉRÔME LEJEUNE}

tigaciones sobre el origen del mongolismo 25 años antes y, si bien había formulado hipótesis interesantes sobre el tema, hasta ahora no había demostrado nada. Su nuevo encuentro del 25 de abril de 1952 con Turpin va a revolucionar su vida. Esa noche escribe a su mujer:

Turpin me propone un trabajo de uno o dos años sobre los mongólicos. Los pequeños retrasados, como ya sabes. Estoy persuadido de que hay algo que tenemos que encontrar y que tal vez sea posible mejorar la vida de miles de seres (solo en Francia ya hay unos 10000 ) si llegamos a encontrar por qué son así. Es un objetivo apasionante que nos pedirá, querida, grandes sacrificios, pero si tú estás de acuerdo en aceptar una vida bastante precaria, pero justa y sana, basada en esa esperanza, yo estoy seguro de que lo conseguiremos. (He empleado el plural, porque solo si tú estás de acuerdo, si me ayudas, llegaré a conseguir algo) ${ }^{4}$.

Y Birthe dice sí. A unos cuantos días de su boda, deciden juntos dedicar su vida y unir sus fuerzas para intentar «mejorar la vida de miles de seres» ¿Cómo? Encontrando las causas de esta discapacidad, y después el tratamiento. ¿Hasta dónde? "Hasta consentir grandes sacrificios, una vida bastante precaria, pero justa y sana, basada en esa esperanza». Una respuesta afirmativa vuelta hacia los otros, por la gracia del amor. "El "si" de Birthe a su novio, el "si" de Jérôme a la demanda silenciosa de esos niños "privados de la libertad del espíritu"». En este compromiso del amor es donde se arraiga la obra de Jérôme y en el que se va a desplegar su vida de médico (p. 47).

La pobreza real en la que viven no merma el entusiasmo ni de Jérôme ni de Birthe, que se disponen a encontrarse con alegría en Dinamarca. Por otra parte, las reticencias iniciales de Massa hacia su futura nuera han dejado paso a un auténtico afecto. Como estaba previsto, la boda tiene lugar con la mayor sencillez el I de mayo, con la madre de Birthe y una amiga de toda la vida que ha venido con su marido; los Lejeune estaban representados por su hermano Philippe con su mujer Geneviève.

En 1952 comienza realmente el despegue de la vida científica y profesional de Jérôme Lejeune, que en aquel verano pasó a ser becario de investigación del CNRS y miembro del servicio del doctor Turpin en el hospital Saint-Louis de París. Su nueva vida profesional consiste, en buena parte, en estudiar con la lupa los dermatoglifos - huellas digitales y pliegues de las manos- de los niños mongólicos. Turpin le ha explicado a fondo que los pliegues de las palmas son un mapa repleto de enseñanzas para aquellos que saben descifrarlos. Los medios con que cuenta el laboratorio son más sucintos de lo que cabría imaginar. En cuanto al personal, es escaso. Jérôme le pide a menudo ayuda a Birthe, que no cuenta las

\footnotetext{
${ }^{4}$ Carta a Birthe, 25 de abril de 1952.
} 
horas que le dedica y le secunda en el estudio de los dermatoglifos. Llega incluso a firmar con su marido una publicación sobre el tema.

Poco después se presenta en la calle Galande una estudiante de medicina de nombre Marie-Odile Rhetoré a la que el padre Ponsar, cura de la parroquia de Saint-Severin, le propone la visita a los enfermos sin recursos del vecindario a través de Lejeune. Jérôme recibe a Marie-Odile $y$, tras conocer su nivel de estudios, le propone unirse al pequeño equipo que se encarga de la asistencia médica a los menesterosos del barrio. A continuación, se reúnen casi cada semana para dar su vuelta por el vecindario. Le propone trabajar con él y acepta (pp. 5I-53).

Birthe da a luz el 27 de enero de 1953 a su primera hija, Anouk: el matrimonio ha decidido poner nombres daneses a las niñas y franceses a los niños. Pasan días sencillos y felices. Mientras que Jérôme estudia los efectos genéticos de las radiaciones ionizantes, esos poderosos rayos que pueden originar recombinaciones químicas en los pobres niños nacidos de padres irradiados, Birthe se dedica a la casa, a su primogénita Anouk y pronto, desde el 27 de abril de 1955, a Damien, nacido en la maternidad de Port-Royal. Menos de dos años más tarde, el 23 de febrero de 1957, nace una nueva niña, Karin, que — se queja Birthetampoco tiene los ojos azules de su padre. Aún nacerán dos más y Lejeune verá cómo concluye su vida rodeado de nietos.

Aquel año no solo trae buenas noticias: en verano Geneviève, la mujer de Philippe, le pidió el divorcio y se marchó, dejando a su marido y a sus tres hijas. Pocos meses después, en enero de 1958, muere de cáncer de pulmón Pierre Lejeune, el patriarca de la familia tan querido por todos. En los últimos instantes, Pierre toma la mano de su hijo y le dice: «iTú sabes amar!»; Jérôme mantiene cogida la mano de su padre y recoge sus últimas palabras. Oye un susurro: «Jesús», después se inclina hacia el oído de su padre y le dice: "Ve con Dios, papá, y gracias». Pero, aunque los meses que siguen son dolorosos para Jérôme, poco a poco, como dice la autora, «la vida reclama sus derechos».

Jérôme está sumergido, desde su entrada en el hospital, en el estudio de los pacientes mongólicos, de los que sabe poco. Estos niños,

heridos en su inteligencia y marcados en su cuerpo, padecen a causa del desconocimiento total que se tiene de ellos, algo que agrava su mal y les llega al corazón. Son los desheredados de la ciencia. Su aspecto físico tan particular, descrito primero por el doctor Seguin en 1844 como «idiocia furfurácea», probablemente en referencia a la blandura de las muñecas de paja, hizo pensar después que mantenían un cierto parentesco con los habitantes de Mongolia, de donde viene el nombre del mongolismo debido a sir Langdon Down, que, en 1866, describió la «idiocia mongólica». Esta clasificación reposa en un grave error científico que ahora 


\author{
EL DR. JÉRÔME LEJEUNE
}

describe Lejeune a su mujer: «¿Sabías que, de momento, la única explicación pseudocientífica que se tiene sobre el mongolismo es totalmente racista? Dicen que esta enfermedad mental procede de la regresión de ciertos caracteres típicos de la raza blanca hacia otra raza. Es francamente urgente encontrar la verdadera causa del mongolismo, porque hay una cosa que es absolutamente segura, y es que jesa causa no es la buena!» (p. 62).

Nuestra enfermedad es ya, desde comienzos del siglo XX, un tema de controversia científica, y se suceden hipótesis jamás confirmadas. En 1937, Turpin y Caratzali pensaban en la posibilidad de una aberración cromosómica y, en 1939, otros dos investigadores de gran reputación, Penrose y Fanconi, llegaban a la misma sugerencia. Estas consideraciones teóricas sobre un posible origen cromosómico del mongolismo fueron abandonadas a continuación. Se busca por todas partes. En total se han propuesto más de sesenta hipótesis diferentes (pP. 6I-62).

A preguntas de Turpin, con quien sigue trabajando, Lejeune le contesta que "demasiadas hipótesis matan la hipótesis» y que él quiere volver a partir de la observación clínica. Así es como, en 1952, Lejeune reemprende el estudio clínico e integra los progresos recientes de la ciencia para intentar encontrar la solución. A partir de 1953, Turpin y él ponen de manifiesto las relaciones de los dermatoglifos (líneas de la mano y huellas digitales) con las características físicas y psíquicas del paciente. Muestran que la estructura de estas líneas, propias de cada persona y que no cambian a lo largo de la vida, está determinada al comienzo del desarrollo del embrión, de manera muy precoz, incluso antes del primer mes in utero. Ahora bien, un estudio profundo ha permitido demostrar que una clasificación de las huellas siguiendo cuatro criterios diagnosticaron el mongolismo de una manera eficaz, en particular con la fusión de dos pliegues de flexión de la palma.

Otra observación, fruto de una conversación con un joven médico del equipo, Jacques Lafourcade, le hace reflexionar:

Es extraño. Los glóbulos blancos de los niños mongólicos tienen una calidad particular y la frecuencia de las leucemias agudas es veinte veces más elevada en ellos que en los niños normales. En consecuencia, parecería lógico suponer que estas dos características pueden ser resultado de un solo y mismo mecanismo: una constitución cromosómica anormal y tal vez desequilibrada.

$Y$ añade: «Y he observado que la influencia de la edad de la madre en la aparición del mongolismo es el único punto en el que los autores parecen estar de acuerdo desde hace cincuenta años». Sigue Lejeune explicando: 
La observación de los embarazos gemelares es igualmente instructiva. A partir de estos estudios parece legítimo concluir que el mongolismo es una afección constitucional. Por consiguiente, el mongolismo es una enfermedad constitucional, determinada antes del $15^{\circ}$ día de la vida in utero, que no aparece de una manera totalmente azarosa, que está influenciada por caracteres no hereditarios y que afecta a un gran número de genes.

\section{$[\ldots]$}

La única hipótesis que puede conciliar estas deducciones aparentemente contradictorias es la de un accidente cromosómico, tal como habían sugerido, ya en 1937, Turpin y Caratsali.

Solo queda probarlo, concluye Lejeune (pp. 62-64).

Estamos en el punto de partida de los progresos científicos de Lejeune en lo relativo al «mongolismo». Entre 1953 y 1957 publica, solo o con Turpin, I3 artículos, que le permiten pasar de ser «becario de investigación» en el CNRS a convertirse en 1954 en «investigador asociado», además de que durante esos años consigue una diplomatura en Genética y otra en Bioquímica. $Y$ ahora llega el verdadero despegue en la investigación de Lejeune y su equipo: desde que Jérôme ha desarrollado la hipótesis del accidente cromosómico como causa del mongolismo, investiga para demostrarlo, y el descubrimiento capital de Levan y Tjio, que prueban en 1956 que las células humanas comportan 46 cromosomas, le brinda nuevas posibilidades. Es preciso comprobar ahora si este es el caso de los niños mongólicos. Para ello, mejora la técnica de cultivo de tejidos y pone a punto una técnica original de coloración de los cromosomas, que facilita su observación.

Tras haber verificado en 1958 el descubrimiento de Levan y Tjio, Lejeune puede aplicarse a la investigación de anomalías cromosómicas en el niño mongólico. En la primavera de 1958, al observar los cromosomas de una célula de tejido de un paciente mongólico consigue, por primera vez en la historia de la medicina, identificar un cromosoma de más. Este se añade aquí al par más pequeño. Lejeune no solo consigue esto, sino que sabe también identificar al responsable de lo que hasta ahora se llamaba "mongolismo» y el que trae consigo un síndrome intersexuado.

A un colega norteamericano, Kurt Hirschhorn, que visita Europa para conocer a los genetistas europeos más destacados, le asombran tanto los descubrimientos del equipo de Turpin-Lejeune como la vetustez de su material. Lejeune se propone entonces hacer una gira por Norteamérica, animado por su maestro Turpin, quien le pide que se informe sobre el equipamiento necesario para continuar con sus investigaciones (pp. 64-75). 


\section{EL DR. JÉRÔME LEJEUNE}

A su vuelta, Lejeune prepara, junto con el resto del equipo, dos notas para la Academia de las Ciencias: la primera, de 26 de enero de 1959, destinada a probar, en tres casos, también con fotografías, que los hasta entonces llamados «mongólicos» tenían claramente 47 cromosomas; el 16 de marzo se publica una segunda nota, que concluye que «el estudio (...) nos ha permitido constatar la presencia regular de 47 cromosomas en nueve niños mongólicos». "En conclusión, pensamos que podemos afirmar que el mongolismo es una enfermedad cromosómica, la primera que ha sido demostrada definitivamente en nuestra especie» ${ }^{5}$.

Pronto aparecen las querellas entre científicos de diversas naciones; pero, como decía por entonces Lejeune, "este asuntillo del cromosoma de más es una historia cerrada. Nada de eso tiene gran importancia, con tal de que se encuentre ahora cómo curar a estos niños». La citogenética acaba de nacer y Jérôme cuenta con un instrumento más para su trabajo: el «Institut de Progénèse», que acaba de crear el gobierno francés y con el apoyo de importantes fundaciones extranjeras.

La autora valora a continuación el interés del descubrimiento, que le parece «inmenso». Por una parte, demuestra, por primera vez en la historia de la medicina, el origen cromosómico de una enfermedad humana y, por otra, prueba la existencia de un mecanismo totalmente desconocido del hombre, a saber: la transmisión de una aberración cromosómica. Pero lo más importante es el cambio consumado para los pacientes, esos para los que trabaja Jérôme. Este descubrimiento libera a los padres de la mirada agobiante de la sociedad, que considera a los niños mongólicos como un castigo a la mala conducta de sus padres. Una mirada, culpabilizadora y mortífera, que lleva a los padres a esconder al niño, convertido en objeto de vergüenza para la familia. Antes del descubrimiento, los padres se encontraban solos frente a la fatalidad, sin ninguna esperanza terapéutica. Ahora bien, al demostrar que se trata de una enfermedad debida a un cromosoma de más, pero no enfermo, sobrevenido por casualidad y no hereditario y menos aun por unos pecados ancestrales, y a lanzar la búsqueda de un tratamiento, Jérôme libra a los padres de ese sentimiento de culpabilidad. Por vez primera, rompe el aislamiento de las familias y les da un poco de esperanza. Ya no se hablará más de mongolismo, sino de trisomía. Estamos en la aurora de una revolución (PP. 8I-82).

\footnotetext{
${ }^{5}$ Lejeune, J., M. Gautier y R. Turpin, «Le mongolisme, maladie chromosomique», Bulletin de l'Académie nationale de médecine, $2^{\circ}$ trimestre, 1959, p. 153.
} 
Siguen los años dorados de Jérôme Lejeune (quien en 1960 declara ante la OMS que su sueño es «hacer que un mongólico sea capaz de ser nombrado profesor de la Facultad de Medicina de París: ese es el sueño de mi existencia» (p. 91), de su familia, que sigue creciendo, y de su equipo de investigación. Crecen las posibilidades de trabajo, se desarrollan los contactos con el extranjero (algunos, como la colaboración con la Fundación Kennedy, especialmente provechosos), las instancias públicas reconocen los éxitos de la citogenética en general y de la francesa, en particular; pero desgraciadamente esos años no van a ser muchos. Hay una fecha clave que cambia por completo el panorama: 1968.

Invitado a formar parte de la Federación Internacional de Sociedades Científicas de Helsinki, le envían con la carta un documento anexo titulado «Toward a new humanity». Contestó diciendo: «Como no puedo suscribir las soluciones teóricas expuestas, por razones tanto científicas como éticas, me es absolutamente imposible asociarme a los fines de su federación». La conversación entre los dos hermanos es de un gran interés y muestra que ya entonces Jérôme pensaba que «no se protege de una desgracia cometiendo un crimen; no se alivia la pena de un ser humano matando a otro ser humano» (pp. |4|-|43). Jérôme es plenamente partidario de la colaboración entre la ciencia y la fe. Pero la sociedad francesa ( $y$ no solo la francesa) se encuentran en plena mutación y la primavera del 68 se anuncia agitada. En la Facultad de Medicina reina un desorden total; pero Jérôme no cede $y$, a pesar de las presiones de los estudiantes, sigue entrando en su despacho. Las cosas están más tranquilas en el hospital NeckerEnfants Malades, donde Lejeune consigue trabajar de una manera casi normal. Más difícil es su esfuerzo para mantener la normalidad en su cátedra de genética; pero va a conseguir que se reemprenda el trabajo y hasta que se hable de su posible nombramiento como decano, hecho que se produce en octubre de aquel año.

En 197I recibirá el prestigioso Allen Memorial Award, pero cada vez se mostrará más pesimista en lo que a lo que podemos llamar «la razón de su vida» se refiere. Lejeune observa desde hace ya algún tiempo en los congresos internacionales una evolución entre sus colegas genetistas que le preocupa profundamente. Son muchos los que se dejan ganar por la corriente eugenésica, que está tomando amplitud y se limita a proponer simplemente el aborto de los niños con discapacidad. En vez de asistirles, se trataría de acabar con su vida por el motivo de que son enfermos. Una solución muy alejada de la medicina de siempre. $Y$ justamente a los niños trisómicos es a los que se apunta en primer lugar, porque se pueden detectar in utero gracias a su descubrimiento de la trisomía 2I. Ahora bien, Jérôme, además del juramento hipocrático que se le impone como médico, quiere a sus pacientes de manera incondicional. Sin condiciones de edad, de peso, de talla, deficiencia o de enfermedad, hasta al más discapacitado, incluso al menos 


\section{EL DR. JÉRÔME LEJEUNE}

deseado. ¿De qué serviría una medicina que no se ocupara más que de los sanos? ¿Qué idea querer suprimir al enfermo cuando no se es capaz de suprimir la enfermedad! Jérôme siente en todo su ser que no puede colaborar en la selección de estos niños enfermos o diferentes. El horror a esta selección prenatal le impacta como una evidencia, y el plazo, antes o después del nacimiento, no cambia nada en el asunto: es lo contrario de la medicina hipocrática y lo contrario de toda fraternidad humana. Jérôme no puede, no podrá nunca. Tiene en el fondo de su corazón ese non possumus que han pronunciado tantos hombres antes que él, cuando no podían aceptar traicionar su conciencia. Una expresión más fuerte y más libre que los emperadores más poderosos. Y este non possumus le pide hoy que dé testimonio, porque no puede dejar de decir lo que ve detrás de este cromosoma suplementario, un niño con sus alegrías y sus penas, y lo que sabe sobre su humanidad y sus derechos inalienables. Su conciencia exige más que un rechazo silencioso, que sería ya un acto de valentía: le pide que tome la defensa de esos niños sin voz anunciando la verdad por ellos y por sus padres (pp. 163165).

Esa es la principal misión que el doctor Lejeune se impone en los años siguientes: la de ser "el abogado de los sin voz»; y lo hace en todos los ámbitos que se le abren, incluso desafiando "a toda la comunidad científica» (p. 168); porque Lejeune sabe que hay otros genetistas que comparten su actitud, pero son pocos los que se manifiestan abiertamente. Su actitud respecto a los niños trisómicos (que no tienen una enfermedad mental) no puede ser más clara: « $\mathrm{O}$ bien les curamos de su inocencia, o bien esto va a ser la matanza de los inocentes» (p. 172). Es consciente de que debe encontrar rápidamente el medio de curarlos, no solo para aliviarles de su enfermedad, sino para salvarlos. Y cuando ya empieza a desesperar, descubre justamente por esta época, en 1970, "una nueva pista de investigación, relacionada con el mecanismo de las sinapsis y el papel de las enzimas en las funciones del cerebro y fabrica de inmediato un modelo molecular» que le puede ayudar a entender $y$ hacer entender la novedad que cree haber encontrado.

Pero su optimismo es de corta duración: lee en Le Monde que el presidente de los médicos de Francia ha implicado a toda la profesión en el proyecto de ley sobre el aborto. Su reacción es rápida: «En nombre de todos los niños afectados por anomalías genéticas y que corren el riesgo de ser asesinados por médicos, tengo el honor de pedirle solemnemente que reúnan al consejo superior del orden [de los médicos] para tratar este proyecto y tengo el deber de pedirle ser oído personalmente, como especialista en esta cuestión. Ni qué decir tiene que, si el consejo del orden aceptara este racismo cromosómico, solicitaré ser borrado de los registros de este orden. No se puede presidir el orden y ser perjuro al juramento de los médicos». No obstante, Lejeune mantendrá una entrevista 
con el presidente de los médicos, el profesor Lortat-Jacob, y le escribe a su mujer para contarle que "la conversación ha ido muy bien y este hombre es honesto. Simplemente le han engañado, y lo sabe muy bien. Me ha dicho que lamentaba que yo no hubiera estado allí, porque él había hablado contra lo que le decía su corazón, creyendo que la ciencia lo había dicho todo" (p. 175). No solo en este caso, sino en tantos otros (incluido el del propio profesor Turpin), los científicos actúan engañados o con miedo a lo que sus colegas o sus representantes parlamentarios puedan decir. Es para Lejeune el momento de la acción pública, que le lleva a conceder entrevistas y participar en debates televisivos, también sobre la eutanasia ${ }^{6}$. Se enfrenta con el principal responsable del proyecto de ley del aborto de los niños discapacitados, el doctor Peyret, en una emisión televisiva en la que este presenta el aborto como un acto profiláctico. La contestación de Lejeune es firme: «Profiláctico no significa matar a los enfermos. Nunca significará eso. Usted nos pide que interpretemos el papel de Poncio Pilato. No hablo desde lo alto de una cátedra, sino de niños de carne y hueso. $Y$ yo no quiero matar a esos niños. Son enfermos". Lejeune da en el blanco, y los oyentes, incluso los más humildes, comprenden que este gran profesor es su amigo. Por eso recibe el agradecimiento de sus pacientes: Hélène, una chica trisómica, le escribe unos días después: "He escuchado la tele. Gracias porque usted quiere a las mongólica».

El ambiente en Francia no cambia apreciablemente en los años siguientes. Respecto al aborto, la derecha no es muy distinta de la izquierda: ahí está Simone Veil, nombrada ministra de Sanidad en mayo de 1974 por el presidente de la República, Valery Giscard d'Estaing, para que su equipo le prepare la ley del aborto junto con Pierre Simon, gran maestro de la Gran Logia de Francia y cofundador del Planning familiar francés. El único ciudadano de prestigio que estará siempre junto a Lejeune es el catedrático calvinista de Historia Moderna Pierre Chaunu. Las vacilaciones dentro de la Iglesia de Francia tampoco ayudan a los católicos de a pie; $y$ a veces no se trata de simples vacilaciones. En diciembre de 1973, Lejeune recibe una llamada de las hermanas del hospital parisino NôtreDame du Bon Secours, que le informan con gran tristeza de que en su hospital se practican abortos y le piden su ayuda. Jérôme solicita inmediatamente una cita con el cardenal Marty, arzobispo de París, dado que el hospital es católico. El

\footnotetext{
${ }^{6}$ Aquí el doctor Lejeune se adelanta, al menos en Francia, a los acontecimientos. A día de hoy, la eutanasia no está aprobada en Francia y, en cambio, están creciendo velozmente los equipos de cuidados paliativos (informe Aceprensa, octubre 202I).

${ }^{7}$ La autora explica que la «s» de «mongólicas» falta en la carta escrita por esta muchacha, la hemos reproducido tal cual. Más emotiva aún es la carta de la madre de Hélène, o de un paciente de Jérôme que acude con sus padres a la consulta del doctor y le dice con emoción: «¡Profesor, defiéndanos!». Su padre le explicó a Lejeune que el chico vio la emisión televisiva.
} 


\section{EL DR. JÉRÔME LEJEUNE}

cardenal no le recibe directamente, sino que le remite a su obispo auxiliar, monseñor Pézeril, quien se encarga de estos asuntos. Cuando se reúnen los dos para analizar el problema, el obispo auxiliar le responde: «Déjelo estar, la ley va a ser votada pronto»; y después, al ver la expresión del rostro de Lejeune, le dice: «Es usted tan intolerante como Louis Veuillot, tan implacable como Bergson, y tan terco como Mauriac. Le digo, ante Dios, que es usted un mal cristiano" (Pp. 219220).

"La batalla de los hijos de Francia» (pp. 205-232) tiene también sus propias expresiones en otras instancias nacionales e internacionales. Una de ellas no puede ser omitida aquí. El 24 de junio de 1974 Jérôme Lejeune recibe una carta del Vaticano por la que el Santo Padre Pablo VI le nombra miembro de la Pontificia Academia de las Ciencias: es el primer paso de una vinculación con la Santa Sede que continuará hasta el fin de su vida; pero, como hemos visto al comienzo de estas páginas, la cosa no quedará allí. No solo dará Lejeune muchas más batallas pacíficas en favor de la vida, sino que se convertirá, como dijo Juan Pablo II, en un verdadero "signo de contradicción» en el mundo y en la lglesia. Por su iniciativa se fundará la Pontificia Academia para la Vida, de la que será primer presidente, y él mismo dará testimonio cristiano en muchos países, sin dejar por ello hasta el final la búsqueda de un remedio para la curación de «sus niños pequeños».

El libro de Aude Dugast merece mucho más que esto, porque es una joya; desgraciadamente, a estas alturas, no puedo sino recomendar vivamente que sea leído. 